\title{
Progress in environmental gentrification research and hotspot analysis based on CiteSpace analysis
}

\author{
Pei Yu, ${ }^{* 1}$ Peng Sun ${ }^{1}$ \\ ${ }^{1}$ School of tourism \& research institute of human geography, Xi'an International Studies University, Shaanxi, China
}

\begin{abstract}
With the advent of the post-industrial era, environmental improvements and sustainable initiatives that lack sufficient attention to the social justice aspects of environmental changes generates environmental gentrification. The purpose of this paper is to systematically explore the frontiers of gentrification research and the knowledge base of environmental gentrification. Therefore, based on Web of Science Core Collection Database, this paper analysed the progress and hotpots of environmental gentrification using CiteSpace, identified keywords relevant to environmental gentrification and their frequency of co-occurrence using the function of keyword co-occurrence analysis, recognized top ten clusters using the function of cluster analysis. Environmental gentrification is the frontier on gentrification research, which knowledge base and hotpots research should arouse our attention. This paper can help readers to understand the status quo and development trend of environmental gentrification better, recognize defect in the development of environmental gentrification, and provide a promising direction for future research.
\end{abstract}

\section{Introduction}

Beginning with Glass's research on urban renewal in the inner city of London in the 1960s, "gentrification" was used to describe the process of the middle class replacing the low-income class ${ }^{[1]}$. Since then, it has become a popular research topic in sociology, geography, urban and rural planning, ecology, economics disciplines and so on. With the diversification and complexity of urban development mechanisms, different types of gentrification have emerged, showing new spatial characteristics and social influences. such as "rural gentrification, student gentrification, tourism gentrification, environmental gentrification". After half a century of development, research on gentrification can be roughly divided into three waves. The third wave of gentrification increasingly uses environmental discourse to change the urban environment ${ }^{[2]}$. With the arrival of the post-industrial era, urban development has increasingly emphasized space and ecological livability. Urban renewal oriented by environmental improvement can bring ecological, social, and economic benefits ${ }^{[3]}$. However, under the leadership of "urban green growth machine coalitions" ${ }^{[4]}$, the government incorporates environmental justice initiatives into economic development opportunities. Most of the environmental improvement projects are implemented by developers oriented by economic interests, ignoring the social and economic vulnerability of original residents. As a result, after the environmental improvement, the ecological elite and high-income groups will move in, and the low-income original residents will be forced to displaced. The creation or restoration of green spaces in low-income areas or locally unwanted land uses (LULUs) may create "green space paradox", that is, environmental gentrification $^{[5,6]}$. Environmental gentrification is an environmental justice issue, Environmental justice not only includes distributional justice, also should rely on procedural justice. In addition, these processes should entails interactional justice ${ }^{[4]}$.

It has been more than ten years since the emergence of environmental gentrification. Scholars have launched a series of studies on this topic and issued a large number of papers. Previous review works on environmental gentrification research were either quantitative ${ }^{[3]}$ or qualitative ${ }^{[7]}$, while no attempt has been made to visualize environmental gentrification knowledge maps. In order to fill this gap, it is necessary to analyze this research by scientometric methods. The literature review is considered to be a way to understand the field of research effectively. CiteSpace software is a visualization software developed by Professor Chen Chao-mei based on Java. It is mainly based on the co-citation analysis theory and pathfinding network algorithm to conduct quantitative analysis of literature in a specific field ${ }^{[8]}$. We can through the visual map to analyze the dynamic mechanism of the discipline evolution and explore the discipline development frontier. The combination of quantification and visualization can help us to further understand environmental gentrification knowledge base in the gentrification area. Based on CiteSpace, this paper conducts statistical and visual analysis on literatures with the theme of "environmental gentrification" obtained from Web of Science databases, to explore the theoretical frontier of human geography and valuable experience of urban renewal.

\footnotetext{
* Corresponding author: sunpeng@xisu.edu.cn
} 


\section{Materials and Mathods}

Based on "space" is the starting and ending point of human geography research. The definition of "environment" is the space in which human live, including "natural, social and psychological", which meaning is broader than "ecology, green" and can cover more issues. Therefore, this article defines the series of phenomena of displacement caused by the improvement of ecological environment and green space as "environmental gentrification". Literature data on environmental gentrification were downloaded from the Web of Science Core Collection Database. With "environmental gentrification", "green gentrification", "ecological gentrification" and "eco-gentrification" as key words for "title" search, obtained 322 direct literatures totally. Then select paper types were "Article", "Review", "Book Review", "Proceedings Paper", "Editorial material" and "Book", the language was "English", 305 literatures were obtained finally. This study uses CiteSpace, V.5.7.R4 (64bit), the parameter selection is top 50 per slice, the time span is 2010-2020 (Slice Length=1), the node types are term and keywords, using the Pruning link in Pathfinder function to do keywords frequency co-occurrence analysis and apply for visualizing co-occurrence networks and research clusters.

\section{Results \& Discussion}

\subsection{Keyword network identification}

Keywords are highly condensed to the research content. The importance of a keyword is usually represented by centrality and there was a positive correlation. Word frequency is the number of occurrences of words in the analyzed literature. The distribution of keyword word frequency can reflect the frequency of citations or the number of articles published in a specific field. In the keyword co-occurrence network mapping, the highfrequency keywords representing research hotpots in the research field can be found by observing the size of keyword nodes. Import the literature data in the WoS database into CiteSpace for conversion analysis, and obtain the mapping keywords frequency co-occurrence (Fig. 1). Keywords frequency co-occurrence is used to detect keywords that appears in at least two different documents within a time period ${ }^{[9]}$. Each node represents a keyword, and the larger the node, the higher the frequency of the keyword. The connecting lines between nodes indicate the co-citation relationship between keywords. The color of the circle layer changes from purple to yellow as time progresses. Therefore, the warmer overall color of the node is, more attention the corresponding keyword has received in recent years. As shown in Table 1, keywords such as "gentrification", "city", "justice", "environmental gentrification", "space", "health", "displacement", "sustainability", "impact" and "community" are relatively large and located near the center of the mapping. It shows that these research topics are the focus of environmental gentrification research.

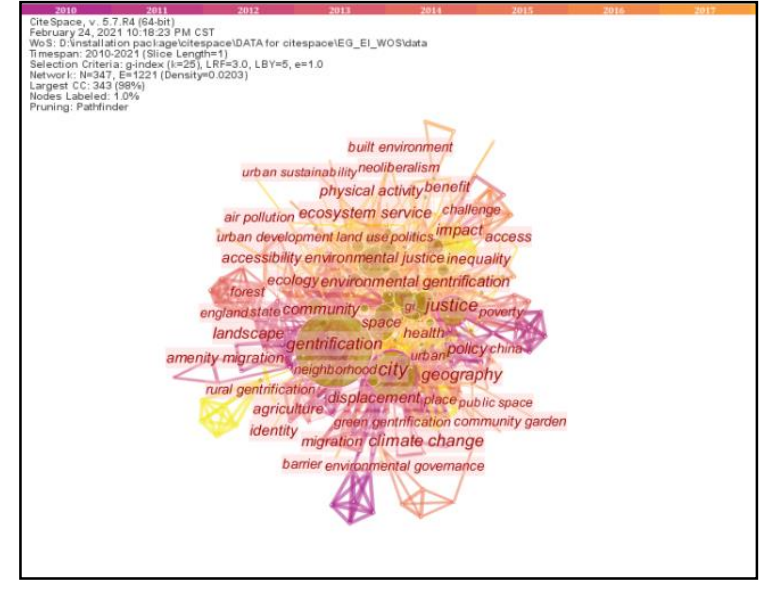

Fig. 1. The mapping keywords frequency co-occurrence

Table 1. Distribution of keywords frequency (top10)

\begin{tabular}{|c|c|c|c|}
\hline No. & Keyword & Frequency & Centrality \\
\hline 1 & Gentrification & 153 & 0.19 \\
\hline 2 & City & 94 & 0.35 \\
\hline 3 & Justice & 42 & 0.23 \\
\hline 4 & $\begin{array}{c}\text { Environmental } \\
\text { gentrification }\end{array}$ & 41 & 0.08 \\
\hline 5 & Space & 37 & 0.10 \\
\hline 6 & Health & 30 & 0.08 \\
\hline 7 & Displacement & 22 & 0.10 \\
\hline 8 & sustainability & 22 & 0.02 \\
\hline 9 & Impact & 21 & 0.14 \\
\hline 10 & Community & 18 & 0.10 \\
\hline
\end{tabular}

In order to deeply analyze the distribution of hot topics and deepen the co-occurrence relationship of themes, bases on the keyword co-occurrence mapping and accords the LLR algorithm to carry out the clustering analysis and produce the keyword co-occurrence cluster mapping

(Fig.2) . Keyword clustering is a kind of mathematical algorithm model to divide the cluster, and then represent the whole characteristics of the knowledge domain. In summary, the research hotpots of environmental gentrification can be roughly divided into three types: the evolution concept, the formation mechanism and the spatial effect of environmental gentrification.

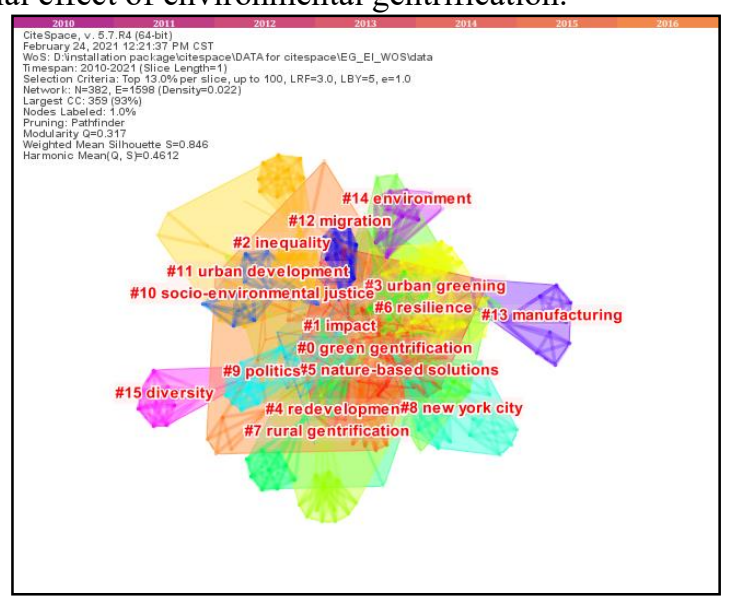

Fig. 2. The mapping keywords co-occurrence cluster 
Table 2. The cluster of keywords co-occurrence (top10)

\begin{tabular}{|c|c|c|c|}
\hline $\begin{array}{c}\text { Cluster } \\
\text { ID }\end{array}$ & Cluster Name & $\begin{array}{c}\text { Cluster } \\
\text { ID }\end{array}$ & Cluster Name \\
\hline$\# 0$ & $\begin{array}{c}\text { Green } \\
\text { gentrification }\end{array}$ & $\# 5$ & $\begin{array}{c}\text { Nature-based } \\
\text { solutions }\end{array}$ \\
\hline$\# 1$ & Impact & $\# 6$ & Resilience \\
\hline$\# 2$ & Inequality & $\# 7$ & $\begin{array}{c}\text { Rural } \\
\text { gentrification }\end{array}$ \\
\hline$\# 3$ & Urban greening & $\# 8$ & New York city \\
\hline$\# 4$ & Redevelopment & $\# 9$ & Politics \\
\hline
\end{tabular}

\subsection{Progress and hotpots analysis}

\subsubsection{The evolution concept of environmental gentrification}

Cluster\#0 and cluster\#7 mainly show the evolution concept of environmental gentrification. Sieg (2004) found low-income communities enjoy improved air quality difficultly when assessed the percentage of annual income paid by different communities in southern California, and called this phenomenon "environmental gentrification" ${ }^{[10]}$. Checker (2011) then defined environmental gentrification as "under the merge of urban renewal, environmental justice activism and ecologically initiatives in an age of advanced capitalism. Operating under the seemingly a political rubric of sustainability, environmental gentrification builds on the material and discursive successes of the urban environmental justice movement and appropriates them to serve redevelopment that displaces low income residents. ${ }^{[11]}$ " Furthermore, scholars put forward concepts such as "ecological gentrification" and "green gentrification". These concepts all involve the core issue of the relationship between urban greening and gentrification. In addition, it can be concluded from Fig. 1 that "amenity migration" is not only the main issue of rural gentrification research, but also the emerging research topic of environmental gentrification.

\subsubsection{The formation mechanism of environmental gentrification}

Cluster\#3, Cluster\#4, Cluster\#6 and Cluster\#9 mainly show the formation mechanism of environmental gentrification. Many studies have shown that there is a connection between environmental gentrification and the creation or renovation of parks, it can bring new capital investment to the community, and lead to an increase in property value and changes in the social nature of communities. These changes may also cause low-income residents to be displaced or marginalized ${ }^{[11,12]}$. Firstly, authors have expressed their opinions on the relationship between the scale and form of green park and gentrification. Some believe that large-scale green spaces are more likely to cause gentrification ${ }^{[3,12,13]}$. However, Rigolon A, Németh J (2019) through analyzing the size of parks and the gentrification of surrounding census areas concluded that there is no significant correlation between the size of park green space and gentrification ${ }^{[14]}$.
Secondly, in terms of the relationship between urban green space location and gentrification, Anguelovski I, Connolly J (2018) research on Barcelona shows that green spaces with active locations promote gentrification ${ }^{[3]}$. Maantay J A, Maroko A R(2018) shows that neighborhood garden proximity is associated with significant increases in per capita income and that existing low-income residents are likely to encounter displacement as the improvement of community environment ${ }^{[15]}$. Thirdly,

similar to other gentrification, there are two viewpoints on the production side and the consumption side to explain the formation mechanism of environmental gentrification. Scholars mostly combine neoliberalism and space production perspective to analyze it. They believe that under the background of neoliberalism, green infrastructure is more cooperative with the market. The government and real estate developers use sustainable discourse to establish new green spaces in areas with insufficient ecological services, and use ecological rent gap to attract wealthy newcomers, eventually making environmental improvement a "green growth machine"[11]. Regardless of whether the production side or the consumption side, there is general agreement on this point that the government played a role in contributing environmental gentrification in the early stage,

\subsubsection{The spatial effect of environmental gentrification}

Cluster\#1 and cluster\#2 mainly show the spatial effect of environmental gentrification. Environmental gentrification will cause positive and negative impacts on society, economy and culture. Supporters often from the ecological, social, economic and other aspects to discuss. In the aspect of ecological benefits, urban green space increases species diversity, slows down the urban heat island effect, and can effectively regulate the environment and climate. As the aspect of social benefits urban green space provides a place for neighborhood activities. Through regular interaction, it strengthens the social relationship between residents and neighbors to enhance the sense of social belonging ${ }^{[16]}$. For the aspect of economy benefits, rich and high-quality urban green space can enhance the brand image of the region, effectively stimulate consumption growth and real estate appreciation, and promote economic upgrading ${ }^{[6]}$. The positive impact of environmental gentrification cannot be ignored, but the negative impact of environmental gentrification also be paid attention to. Immergluck D, Balan T (2018) found project that abandoned infrastructure into important green spaces is the urban sustainable development plan. While make the city more livable and resilient, many projects have also led to displacement of residents along the project, which is bad for environmental justice and exacerbated social inequities ${ }^{[12]}$. Anguelovski I, Connolly J J T, Masip L (2018) argues that without a critical discourse on the environmental gentrification, sustainable development is likely to be reduced to a tool to promote a green lifestyle, attracting only affluent residents. They calls for the construction of models to explore whether the distribution 
of environmental facilities becomes more equitable ${ }^{[3]}$. Pearsall H (2010) in order to identify groups vulnerable to negative impacts during brownfield redevelopment, applied vulnerability assessment approach to the sustainable development initiative for contemporary society in New York City ${ }^{[17]}$.

\section{Conclusions}

The unique value of this paper is to explore the hotspots in the field of environmental gentrification based on keywords and terms using the function of quantitative analysis of CiteSpace. At present, there is a big gap between the depth and breadth of the study on environmental gentrification in China and abroad. Future theoretical and empirical work could assess the social sustainability indicators in urban development plans to see to what extent they capture complex concepts of social justice, and whether they lead to positive changes in social equity. In urban renewal, in order to promote social equity in redevelopment projects, specifically to allow long-term residents to benefit from improved economic and environmental conditions, more policy-driven research is needed to explore how to mitigate the negative effects of environmental gentrification.

\section{Acknowledgments}

This research was supported by 2019 Federation of Social Science Foundation of Shaanxi Province (2019C129), 2020 Social Science Planning Foundation of Xi'an (JG90), 2021 Shaanxi Province Soft Science Research Project(2021KRM152) and Postgraduate Foundation of Xi'an International Studies University (SYJS201833, SSZD2019030).

\section{References}

1. R. Glass London: Aspects of Change[M]. xiiixlii,(1964).

2. N. Quastel. Political Ecologies of Gentrification[J]. Urban Geography, 30,7(2009).

3. I. Anguelovski, J.Connolly, L,Masip et al. Assessing green gentrification in historically disenfranchised neighborhoods: a longitudinal and spatial analysis of Barcelona[J]. Urban Geography, 39,7(2018).

4. A. Rigolon, J. Németh. "We're not in the business of housing:" Environmental gentrification and the nonprofitization of green infrastructure projects[J]. Cities, 81(2018).

5. H. Pearsall, J K.Eller. Locating the green space paradox: A study of gentrification and public green space accessibility in Philadelphia, Pennsylvania[J]. Landscape and Urban Planning, 195(2020).

6. I. Anguelovski. From Toxic Sites to Parks as (Green) LULUs? New Challenges of Inequity, Privilege, Gentrification, and Exclusion for Urban Environmental Justice[J]. Journal of Planning Literature, 31(2015).
7. I. Anguelovski, J. Connolly et al. New scholarly pathways on green gentrification: What does the urban 'green turn' mean and where is it going? [J]. Progress in Human Geography, 43,6(2019).

8. C M. Chen. CiteSpace II: Detecting and visualizing emerging trends and transient patterns in scientific literature $[\mathrm{J}]$. Journal of the American Society for Information Science and Technology. 57,3(2006).

9. C, Chen Z, Hu, S,Liu et al. Emerging trends in regenerative medicine: a scientometric analysis in CiteSpace [J]. Expert Opinion on Biological Therapy, 12,5(2012).

10. H,Sieg, V K,Smith. H S.Banzhaf. Estimating the general equilibrium benefits of large changes in spatially delineated public goods[J]. International Ecomomic Review, 45,4(2004).

11. M. Checker Wiped Out by the "Greenwave": Environmental Gentrification and the Paradoxical Politics of Urban Sustainability[J]. City \& Society, 23,2(2011).

12. D, Immergluck, T. Balan. Sustainable for whom? Green urban development, environmental gentrification, and the Atlanta Beltline $[\mathrm{J}]$. Urban Geography, 39,4(2018).

13. A, Rigolon, J.Nemeth "We're not in the business of housing:" Environmental gentrification and the nonprofitization of green infrastructure projects[J]. Cities, 81(2018).

14. A, Rigolon, J. Németh Green gentrification or 'just green enough': Do park location, size and function affect whether a place gentrifies or not?[J]. Urban Studies, 57,2(2019).

15. J A, Maantay, A R. Maroko. Brownfields to Greenfields: Environmental Justice Versus Environmental Gentrification[J]. International Journal of Environmental Research and Public Health, 15,10(2018).

16. A C K, Lee. M. Raheswaran. The health benefits of urban green spaces: a review of the evidence[J]. Journal of Public Health, 33,2(2011).

17. H. Pearsall. From brown to green? Assessing social vulnerability to environmental gentrification in New York City[J]. Environment and Planning C: Government and Policy,28 (2010). 